\title{
MJMR DISASTER PREPAREDNESS AWARENESS AMONG CRITICAL CARE NURSES AT A TERTIARY HOSPITAL IN PAHANG, MALAYSIA
}

\author{
Nurul Aqila Azali ${ }^{1}$, Salizar Mohamed Ludin ${ }^{2 *}$ \\ Resch Scholar, Kulliyyah (Faculty) of Nursing, International Islamic University Malaysia \\ Associate Professor, Depertment of Critical Care Nursing, Faculty of Nursing, International Islamic \\ University Malaysia \\ Corresponding Author E-mail: msalizar@iium.edu.my
}

\begin{abstract}
Background: Disaster preparedness should be taken seriously as preventive measures and it is one of the elements in the disaster risk reduction framework but the status the country is unknown. Methods and Materials: A cross-sectional study was done using Disaster Preparedness Evaluation Tool to investigate the relationship between factors contributing to disaster preparednessof on 125 critical care nurses toward their preparedness in a disaster. Findings: Thefacility where the nurses workshowed significant contributionto disaster preparedness $(p<0.05)$. Variables that shows strong relationship and positively correlated are knowledge $(\mathrm{r}=0.654, p=0.001)$, skills $(r=0.727, \mathrm{p}=0.001)$ and perception: $r=0.737, p=0.001)$. Discussion: The finding is similar to (Tzeng et al., 2016) that found disaster preparedness to have a significant association with participants' educational level, emergency or intensive care experience, number of years in nursing and their background. Disaster experience was found to be influencing the willingness to respond (Goodhue, et al., 2012; Baack and Alfred, 2013). (Sonneborn, Miller, Head, and Cross 2018) also emphasized the nurses' required disaster training annually. Conclusion: Overall, there was a significant association between the level of knowledge, skills and perception toward disaster preparedness with the level of disaster preparedness. Training is needed to create awareness and preparedness.
\end{abstract}

\section{Keywords: Disaster Preparedness, Critical Care Nurses, Awareness}

\section{INTRODUCTION}

According to (International Strategy for Disaster Reduction, 2013), disaster was well-defined as "a severe interruption of the effectiveness of society, causing pervasive human, material, or environment damages, which went beyond the capability of the affected society to handle, consuming only its own resources". Examples of natural disasters are such as storms, floods and earth-quakes; meanwhile, there are also man-made disasters like war, pollutions and explosions. All these events had given a great impact on the environment and, later on, harm all living things including humans. Recently, on October $25^{\text {th }}, 2016$, surprisingly, the worst fire happened at one of the ICU in a tertiary hospital in the country that claims six patients' life that were fully dependent on the ventilator and could not move.
Disaster preparedness among healthcare groups are very important as they are the frontline responsible to save patients who are unconscious, could not move and in pain. "Preparedness needs a functioning focused approach on the growth of formal actions and strategies episodes, even during the time when there are no threats or outbreaks", (Belfroid et al., 2017) According to (Labrague, Yboa, McEnroe-Petitte, Lobrino, and Brennan 2016), it is very critical for nurses and other healthcare workers to be ready and prepare to play their roles and help maintain the stability of the patients. Furthermore, the department of intensive care unit and emergency is an essential place which is located in need attention patient.

Eloquently stated by (Corrigan and Samrasingha 2012), they indicated that front-line medical and nonmedical hospital staffs were poorly trained and seemed 
unprepared in responding to any important disaster ( $\mathrm{p}$. 436). In order to recover the safety of the people in the hospital during a disaster, healthcare workers, especially nurses, who are close to the patients must be equipped with knowledge about the disaster plan. If they were well trained in facing something like a real disaster, it could build confidence and help them in applying the knowledge and save lives (Lim, Lim \& Vasu, 2013).

In recent studies, (Alzahrani and Kyratsis 2017) had reasserted the nurses who were working in the critical care area, particularly those in an emergency department, to not only have knowledge but also skills and experience to manage emergencies efficiently and cope with any chaotic circumstances like a disaster (p. 2). Apart from having a disaster plan, it was also very significant for hospitals to have regular updates and drills to test their readiness in handling a disaster in the future (Labrague et al., 2016). It is not enough with just having knowledge and skills, the nurses must practice regularly to polish what they had.

(Labrague et al. 2016) indicated that the nurses were not prepared to play their role if there was a disaster in their workplace as they did not have the sufficient knowledge and skills (p.99). "Nursing and medical personnel played vital roles in situations involving human lives during a disaster, yet, they received little training on disasters which results in low levels of consciousness due to less exposure" (Ahayalimudin \& Osman, 2016, pp. 1-2). (Belfroid et al. 2017), in their study by the healthcare organization preparedness experts were about the evaluation of the level of preparedness. (May,Colbert, Rea, Wood, and NaraVenkata, 2015), they related that the experience and training influenced the disaster preparedness of staffs in the hospital, but, the study could not be generalized to other hospital sectors as it was a small sample size of respondents (p. 918).

According to (Labrague et al. 2016), it was very critical for nurses and other healthcare workers to be ready and prepare to play their roles and help maintain the stability of the patients. "Preparedness needs a functioning focused approach on the growth of formal actions and strategies episodes, even during the time when there are no threats or outbreaks" (Belfroid et al.,
2017, p. 1).Thus, this study aims to identify the level of knowledge, skills, and perception of disaster preparation among critical care nurses at a tertiary hospital.

\section{METHODOLOGY}

A cross-sectional study was done in the critical care areas at the hospital. In the first phase, the researchers needed to identify suitable participants according to inclusion and exclusion criteria as sample for the research. The researcher gave an envelope consisting of sets of questionnaires with an information sheet and a written consent form attached to each set. The second phase, the questionnaires were distributed to the respondents within 2 months. Following that, all the data were combined, descriptive as well as inferential analyses were conducted using the Statistical Package for Social Science (SPSS) software version 20.0. The $p$-value was set at 0.05

A total of 141 staff nurses met the inclusion criteria for this study without knowing their limitations. Only 125 completed the Disaster Preparedness Evaluation Tool and returned it back (response rate: 88.6\%). The participants of this study were convenience sampled and recruited due to a limited number of critical care nurses. The inclusion criteria of this study were; (a) RN U29 and U32, (b) work in ICUs, PICU, NICU and $\mathrm{CCU}$, (c) with more than 6 months working experience, (d) able to understand and read, (e) agree to participate and (f) all the races were included. Meanwhile, the exclusion criteria: nurses who were on long leave (maternity, study and unpaid leave) and (b) worked for less than 6 months.

The Disaster Preparedness Tool questionnaire (Al Khalaileh et al., 2012)used in this study consist of 66 questions. But, in this study, there were only 61 questionnaires because of the adjustments made to the questionnaires for critical care nurses. The first section had 45 questions that were measured using six-point Likert Scale and were divided into 3 parts, the first part consisted of 25 items related to Pre-disaster preparedness stage (categories: knowledge, disaster skills and perception about personal preparedness); second part, 14 items related to Mitigation and response stage (categories: knowledge, disaster skills and 
perception about personal preparedness); and part three included 6 items related to Evaluation stage (categories: knowledge, disaster skills and perception about personal preparedness). The Likert scale was ranged from 1 - Strongly disagree, 2- Disagree, 3-Weakly disagree, 4-Weakly Agree, 5- Agree, and 6- Strongly Agree. Section 2 had 16 questionnaires related to sociodemo graphic data.

The study was approved by the university Research Ethic Committee, and Medical Research and Ethics Committee (MREC). Permission also obtained from participants to participate in the study by giving a written consent form for them to sign; the details about the participants were disclosed and kept confidential for the sake of the study only and they had right to refuse from being a participant in the study if they thought the study would not bring any benefit to them or the community; there were no penalties or consequences if they withdrew from the study.

\section{RESULTS}

\section{Socio-demographic characteristics}

Years of experience as a critical care nurse among staff nurses

Most respondents were those who had experiences of more than 10 years $(n=51,40.8 \%)$, meanwhile, the smallest number was from staff nurses who had experiences between 6 months to 1 year $(n=12,9.6 \%)$.

The educational level included diploma holders which were 106 nurses (85\%), 4\% staff nurses who already had post basic and the bachelor holders were 14 nurses (4\%). The facility the staff nurses were employed in consisted of ICU $1(n=42,33.6 \%)$, ICU $2(n=22,17.6 \%)$, PICU $(n=23$, $18.4 \%), \operatorname{NICU}(\mathrm{n}=28,22.4 \%)$ and $\mathrm{CCU}(\mathrm{n}=10,8.0 \%)$.

There were five types of facilities in the critical care department involved in this research study, they were the ICU 1, ICU 2, PICU, NICU, and CCU (Table 4.2.4.4), the mean (M) was 2.54 and Standard Deviation (Std. Dev.) was 1.365 from a total of 125 respondents. The biggest number of respondents was shown by staff nurses employed in ICU 1, which was 42 people (33.6\%). On the other hand, only $8.0 \%(n=10)$ of CCU nurses participated in the study from the total number of staff nurses in the Critical Care department $(\mathrm{N}=125)$.

Table 1: Socio-demographic Characteristics

\begin{tabular}{|c|c|c|c|c|c|}
\hline $\mathrm{N}=141$ & Variables & Frequency (n) & Percentage (\%) & Mean & Standard \\
\hline \multirow{4}{*}{$\begin{array}{l}\text { 1) Experience as a staff } \\
\text { nurse }\end{array}$} & 6 months- 1 year & 1 & 0.8 & 2.26 & 0.782 \\
\hline & 1 years -5 years & 23 & 18.4 & & \\
\hline & 6 years- 10 years & 44 & 35.2 & & \\
\hline & More than 10 years & 57 & 45.6 & & \\
\hline \multirow{4}{*}{$\begin{array}{l}\text { 2) } \begin{array}{l}\text { Experience as a } \\
\text { critical care nurse }\end{array}\end{array}$} & 6 months -1 year & 12 & 9.6 & 1.95 & 1.031 \\
\hline & 1 years- 5 years & 33 & 26.4 & & \\
\hline & 6 years- 10 years & 29 & 23.2 & & \\
\hline & More than 10 years & 51 & 40.8 & & \\
\hline \multirow[t]{2}{*}{ 3) Gender } & Male & 2 & 1.6 & 0.98 & 0.126 \\
\hline & Female & 123 & 98.4 & & \\
\hline \multirow{3}{*}{$\begin{array}{l}\text { 4) Educational } \\
\text { level }\end{array}$} & Diploma & 106 & 84.8 & 0.26 & 0.649 \\
\hline & Bachelor & 5 & 4.0 & & \\
\hline & Others & 14 & 11.2 & & \\
\hline \multirow[t]{5}{*}{ 5) Facility } & ICU 1 & 42 & 33.6 & 2.54 & 1.365 \\
\hline & ICU 2 & 22 & 17.6 & & \\
\hline & PICU & 23 & 18.4 & & \\
\hline & $\mathrm{NICU}$ & 28 & 22.4 & & \\
\hline & $\mathrm{CC}$ & 10 & 8.0 & & \\
\hline
\end{tabular}


The relationship between sociodemographic characteristics and the level of disaster preparedness

One-way ANOVA (table 2) used to measure the association between sociodemographic characteristics and the level of disaster preparedness. According to the table, there was a significant difference between the type of facility the staff nurses are employed in with $p=$ $0.045(p<0.05)$. It showed that the disaster preparedness among nurses was different based on where they were employed. Meanwhile, years of experience as critical care nurses and educational level did not have a significant difference with the level of disaster preparedness.

Table 2: Relationship between Sociodemographic Characteristics and the Level of Disaster Preparedness

\begin{tabular}{|c|c|c|c|c|c|c|}
\hline & & Sum of Squares & $\mathrm{df}$ & Mean Square & $\mathrm{F}$ & Sig. \\
\hline \multirow[t]{3}{*}{$\begin{array}{l}\text { Years of services as critical care } \\
\text { nurses }\end{array}$} & Between Groups & 4.056 & 2 & 2.028 & 1.938 & 0.148 \\
\hline & Within Groups & 127.656 & 122 & 1.046 & & \\
\hline & Total & 131.712 & 124 & & & \\
\hline \multirow[t]{3}{*}{ Education level } & Between Groups & 0982 & 2 & 0.491 & 1.167 & 0.315 \\
\hline & Within Groups & 51.306 & 122 & 0.421 & & \\
\hline & Total & 52.288 & 124 & & & \\
\hline \multirow[t]{3}{*}{ Type of facility } & Between Groups & 11.464 & 2 & 5.732 & 3.184 & 0.045 \\
\hline & Within Groups & 219.624 & 122 & 1.800 & & \\
\hline & Total & 231.088 & 124 & & & \\
\hline
\end{tabular}

The relationship between factors contributing to disaster preparedness

Based on table 3, all the variables had a positive significant and a strong relationship within variables. The knowledge variables had a strong relationship and are positively correlated at $\mathrm{r}=0.654, p=0.001$. Skills variables had a strong relationship and are positively correlated at $\mathrm{r}=0.727, \mathrm{p}=0.001$. Perception variables also had a strong relationship and are positively correlated at $r=0.737, p=0.001$.

Table 3. The relationship between factors contributing to disaster preparedness

\begin{tabular}{|c|c|c|c|c|c|}
\hline & & Level of disaster preparedness & Knowledge & Skills & Perception \\
\hline \multirow[t]{3}{*}{ Knowledge } & Pearson Correlation & $0.654^{* *}$ & & & \\
\hline & Sig. (1-tailed) & 0.000 & & & \\
\hline & $\mathrm{N}$ & 125 & & & \\
\hline \multirow[t]{3}{*}{ Skills } & Pearson Correlation & $0.727^{* *}$ & $0.252^{* *}$ & & \\
\hline & Sig. (1-tailed) & 0.000 & 0.002 & & \\
\hline & $\mathrm{N}$ & 125 & 125 & & \\
\hline \multirow[t]{3}{*}{ Perception } & Pearson Correlation & $0.737^{* *}$ & $0.176^{*}$ & $0.319^{* *}$ & \\
\hline & Sig. (1-tailed) & 0.000 & 0.025 & 0.000 & \\
\hline & $\mathrm{N}$ & 125 & 125 & 125 & \\
\hline
\end{tabular}




\section{Regression analysis}

Based in table 4 , all variables were statistically significant at 5\% significance level with adjusted Rsquared of $60.7 \%($ F-value $=62.365 ; p$-value $=0.001)$ and with adjusted R-squared of $59.8 \%$ ( $F$-value $=$ $62.365 ; p$-value $=0.001)$ for level of disaster preparedness among the nurses. This result suggested that $59.8 \%$ in the level of disaster preparedness could be explained by demand, control and support as a control variable.

Table 4. Association between Level of Disaster Preparedness and each Linear Regression Independent Variables

\begin{tabular}{|c|c|c|c|}
\hline \multirow[t]{2}{*}{ Variables } & \multicolumn{3}{|c|}{ Level of Disaster Preparedness } \\
\hline & Coefficient (Beta) & $t$-statistic & $P$-value \\
\hline Intercept & & -3.009 & 0.003 \\
\hline KNOWLEDGE & 0.234 & 3.905 & 0.000 \\
\hline SKILLS & 0.389 & 4.729 & 0.000 \\
\hline PERCEPTION & 0.344 & 4.257 & 0.000 \\
\hline $\mathrm{R}^{2}$ & 0.607 & & \\
\hline Adj. $R^{2}$ & 0.598 & & \\
\hline F-statistic & 62.365 & & \\
\hline (P-value) & 0.000 & & \\
\hline Df & $(3,121)$ & & \\
\hline $\mathrm{N}$ & 60 & & \\
\hline
\end{tabular}

\section{DISCUSSION}

\section{Nurses' sociodemographic characteristics}

In this study, most of the participants were female nurses which were 123 compared to male nurses. It was similar with a study conducted by (Hammad, Arbon, and Gebbie 2010), it was said that most of the participants were females. The researcher in this study found that there was a significanceassociation between type of facility and level of preparedness. The facilities were divided into ICU, PICU, NICU and CCU. Meanwhile, the other two components of sociodemographic characteristics which were years of experience as critical care nurses and the educational level were not significant to the level of disaster preparedness.

The finding of this study is similar to (Tzeng et al., 2016) finding that found disaster preparedness shown by the participants had a significance association with educational level, emergency or intensive care experience, number of years of nursing experience and a military background. They also revealed that the nurses who had clinical experience for more than 10 years displayed better self-reported scores in emergency response than nurses with less than 10 years of clinical experiences. For the relationship between sociodemographic characteristics and the level disaster preparedness, the participants who had experience in real disasters showed highest scores in the four domains of the level of disaster preparedness in their study compared to those who were never involved in a real disaster as reported by (Baack and Alfred 2013). A study which had the same result was by (Goodhue et al. 2012), the disaster experience influenced the willingness to respond.

\section{The level of knowledge and disaster preparedness}

In this study, the researcher found that there was a significant association between level of knowledge and disaster preparedness with a strong positive relationship between variables with $r=0.654, p=$ 0.001 . Based on the level of knowledge questionnaires, most of the participants perceived they had a high level of disaster preparedness as they had participated in disaster drills or exercises in their workplace with $\mathrm{M}=$ 4.68. According to (Hammad et al., 2010), the nurses in Australia have a low level of disaster knowledge and although most of the nurses have completed their disaster training and education, questions have been raised regarding the appropriateness and relevance of the education.

The other findings of this study showed that the nurses had difficulty in finding relevant information about disaster preparedness relating to their community needs, $M=4.07$. The same findings were obtained by (Sangkala and Gerdtz 2018), as the nurses had difficulties in searching for information about disaster preparedness and management. Furthermore, (Usher et al., 2015), in their study stated that it was not easy for nurses from Bangladesh, Laos and the Solomon Islands to find 
relevant research information related to disaster preparedness. (Hammad et al., 2010) also found that the respondents considered themselves weakly prepared because they thought that it was difficult to find relevant information about disaster preparedness relating to their community needs (Median=2, IQR-2-3).

In order to improve disaster education among nurses, further research should focus on the development of a framework to be utilized in disaster preparedness education for acute departments like the emergency, intensive care unit, and Operation Theater (Sonneborn, Miller, Head \& Cross, 2018). Other than that, the hospital management should organize a class or seminar for healthcare workers, (Al-Ali and Ibaid 2015), 67.6\% of participants expressed a need for disaster education regarding psychological interventions needed during the recovery stage of a disaster, such as managing acute stress disorder, crisis intervention as focused assessment, debriefing strategies, and behavioral cognitive and medication therapies.

\section{The level of skills and disaster preparedness}

Based on the Pearson correlation, there was a strong positive correlation between the level of skills and disaster preparedness at $\mathrm{r}=0.727, p=0.001$. The respondents are highly aware of any potential vulnerability in their community area like earthquakes, floods and fires $(M=4.53)$. Most of the respondents obtained their skills in disaster during disaster education during their study life, which is $54.4 \%$ compared to those who were involved in a real disaster which was only $8.8 \%$. Meanwhile, they were poorly prepared to be a key leadership figure in their community in a disaster situation $(\mathrm{M}=3.13)$, this finding is the same as the results found by (Sangkala and Gerdtz, 2018). The participants in the research study except for Cambodia, thought themselves as poorly prepared to participate in creating new guidelines, emergency plans, or lobbying for improvement in the local or national level (Usher et al., 2015).

(Alfred et al., 2015), feeling unconfident in disaster skills because of lack of involvement of health care provider to competency-based training which could help to enhance their skills in managing the disaster.
Furthermore, the nurses perceived that by having disaster training is also associated with an increase of disaster respond willingness (Goodhue et al., 2012, Lim et al., 2013). One of the suggestions from Al Ali and Ibaid (2015) in their study was that most of the participants believed that training courses on managing all kinds of disasters and introducing practical guidelines for disaster management.

Moreover, the skills obtained by the nurses should be practiced and trained regularly to improve their skills and be more prepared. Based on the study conducted by (Tzeng et al. 2016), the nurses showed poor disaster preparedness due to limited bioterrorism-related training continuing their education programs in Taiwan. Besides that, half of the nurses $(42 \%, n=83)$ reported that they had not received any disaster training for 12 months or more, meanwhile, the other $18 \%(n=35)$ had never received any disaster training. A study by (Sonneborn et al. 2018) also emphasized that nurses required disaster training annually $(90.0 \%)$.

\section{The level of perception towards disaster preparedness}

In the study, there was a significant relationship between the level of perception and disaster preparedness with strong positive correlation at $\mathrm{r}=$ $0.737, p=0.001$. The nurses in the critical care unit had high disaster preparedness as they had high confidence in their abilities as a direct care provider and first responder in the disaster situation, $\mathrm{M}=4.35$. Meanwhile, the findings from the study conducted by Jorgensen, Mendoza, and (Henderson, 2010), showed that the perception of personal safety and family safety could determine nurses' willingness to respond to work during a disaster or public health emergency.

The respondents in the study were less familiar with how to perform a focused health assessment for Posttraumatic stress syndrome $(M=3.34)$. The other study by (Sangkala and Gerdtz 2018) supported the finding, the lowest confidence of the respondents was at managing skills related to psychological interventions and post-traumatic stress syndrome management. These findings showed that the staff nurses need improvement in their preparedness regarding mental health nursing after a disaster because it was one of the great burdens for disaster victims. The psychological 
domain in the study by (Yan, Turale, Stone, and Petrini 2015) included psychological endurance and adjustment ability, psychological guidance skills, good psychological quality and psychological counseling skills.

In this study, the nurse had higher confidence in disaster preparedness as they were familiar with their assigned role as a nurse in a disaster situation $(\mathrm{M}=$ 3.69). The result was similar to (Goodhue et al., 2012), the most significant factor which increased the nurses responding to a disaster event was having an assigned role in the workplace disaster plan.

Disaster response training, access to hospital disaster response plans, personal knowledge in disaster response and family support affected the perception of individual preparedness (Lim et al., 2013). Based on the result from the study, knowledge and skills in disaster had a significance with the nurses' perception and confidence in disaster preparedness $(p<0.001)$. (Al-Ali and Ibaid, 2015), their study showed that participants who had training drills in the workplace $(p<0.001)$ and knowledge $(p<0.001)$ perceived themselves as well prepared in a real disaster.

\section{Limitations}

The study was conducted in the critical care unit of one hospital only and the sample size was small. The generalize ability of the study findings to all staff nurses in other places may be limited as indeed the external validity was impacted with respect to other acute care areas and other hospitals. Other than that, there was also the potential for a sampling bias as this study used convenience sampling where the respondents had a low response rate and a voluntary nature to answer the survey form.

\section{Recommendations}

Nursing education must expose disaster knowledge since it is good to give a good picture of it when nurses are studying. It must be one of the subjects to learn for all nursing students. Then, disaster knowledge must be delivered continuously even if the nurses are already in their working area. Effective education relies on planning that ensures relevance of the content, teaching and learning strategies that effectively deliver the content and evaluation of the participants to confirm they are able to assist others in gaining the necessary knowledge and skills (Jorgensen et al., 2010). The contents of the disaster education must be suitable to be implemented in the hospital and the staff nurses should understand their role in gaining more knowledge to help their community.

The nursing skills must include disaster skills and is polished regularly as the hospital management suggested conducting a training class at least once a year to make sure the staff nurses maintain their skills. Nursing practice related to disaster management is very crucial as it can help the staff nurse know their roles and responsibilities during a real disaster. "Even if a disaster rarely occurs but it is better to provide health care providers with appropriate education and training", (Hammad et al., 2010). The training should not include physical treatment only but also the management of the psychological aspect of staff nurses and victims. The psychological endurance during a disaster for staff nurse is very important as they are the backbone in creating a safe environment for the victims.

The government must have the initiative to support nursing research regarding disaster and give opportunities for the nurses to contribute to their own community. Nursing research can enhance disaster management in the future. For example, the government can give a chance in giving funds for nurses to do the research study.

\section{CONCLUSION}

In conclusion, the study had achieved its objectives which were to explore the nurses' disaster preparedness based on sociodemographic criteria, level of knowledge, level of skills and their perception towards disaster preparedness in a critical care setting. The sociodemographic characteristics included three aspects, which were years of experience as critical care nurses, education level and type of facility the nurses were working in. Thus, only the type of facility the nurses were working in was significant to disaster preparedness. It indicated that each facility had different levels of disaster preparedness. Moreover, the level of knowledge, skills and the nurses' perception toward disaster preparedness had a significance with disaster preparedness. The Pearson correlation showed that if the nurses had a high level of these three, their disaster preparedness also increased. 
Thus, it is very important for the management of hospitals to build strategies and management strategies to improve the nurses' knowledge, skills and confidence consistently. It is very helpful for the hospital, staff, and community if a disaster were to happen in the future

\section{ACKNOWLEDGMENTS}

We would like to thank all the participants and those who have contributed to this study, including the government and non-government bodies.

\section{Declaration of Conflicting Interests}

The author(s) declared no potential conflicts of interest with respect to the research, authorship, and/or publication of this article.

\section{Funding}

None

\section{Ethical Approval}

NMRR-18-159-39620 (IIR)

\section{CONFLICT OF INTERESTS}

The authors declare that they have no conflict of interest.

\section{REFERENCES}

Ahayalimudin, N.A. \& Osman, N.N.S., (2016) Disaster management: Emergency nursing and medical personnel's knowledge, attitude and practices of the East Coast region hospitals of Malaysia. Australasian Emergency Nursing Journal, 19(4), pp:1-7.

Al Khalaileh, M.A., Bond, E., Alasad, J,A., (2012) Jordanian nurses' perceptions of their preparedness for disaster management. International Emergency Nursing, 20(1), pp:14-23.

Al-Ali, N., Abu Ibaid, A.H., (2015) Health-care providers' perception of knowledge, skills, and preparedness for disaster management in primary health-care centres in Jordan. Eastern Mediterranean Health Journal, 21(10), pp:713-721.

Alfred, D., Chilton, J., Connor, D., Deal, B., Fountain, R., Hensarling, J., \& Klotz, L., (2015) Preparing for disasters: Education and management strategies explored. Nurse Education in Practice, 15(1), pp:82-89.
Alzahrani, F., \& Kyratsis, Y. (2017), Emergency nurse disaster preparedness during mass gatherings: A cross-sectional survey of emergency nurses' perceptions of hospitals in Mecca, Saudi Arabia. BMJOpen, 7, e013563.

Baack, S., \& Alfred, D. (2013), Nurses' preparedness and perceived competence in managing disasters. Journal of Nursing Scholarship, 45(3), pp:281-287.

Belfroid, E., Timen, A., van Steenbergen, J.E., Huis, A., \& Hulscher, M.E., (2017), Which recommendations are considered essential for outbreak preparedness by first responders? BMC Infectious Diseases, 17(1), pp:95.

Corrigan, E., Samrasinghe, I. (2012), Disaster preparedness in an Australian urban trauma center: Staff knowledge and perceptions. Prehospital and Disaster Medicine, 27(5), pp: 432-438.

Goodhue, C.J., Burke, R.V., Ferrer, R.R., Chokshi, N.K., Dorey, F., \& Upperman, J.S. (2012), Willingness to respond in a disaster: A pediatric nurse practitioner national survey. Journal of Pediatric Health Care, 26(4), e7-20.

Hammad, K.S., Arbon, P., Gebbie, K.M. (2010). Emergency nurses and disaster response: An exploration of South Australian emergency nurses' knowledge and perceptions of their role in disaster response. Australasian Emergency Nursing Journal, 14(2), pp: 87-94.

Henderson,J.C. (2010), Sharia-Compliant Hotels, Tourism and Hospitality Research, 2010(10) pp: 246-254

International Strategy for Disaster Reduction. (2003). UN-ISDR: Terminology on disaster risk reduction (working document). Retrieved from http://www. adrc.asia/publications/terminology/top.htm

Jorgensen, A.M., Mendoza, G.J., Henderson, J.L. (2010), Emergency preparedness and disaster response core competency set for perinatal and neonatal nurses. Journal of Obstetric, Gynecologic\& Neonatal Nursing, 39(4), pp: 450-467.

Labrague, LJ., Yboa, BC., McEnroe-Petitte, DM., Lobrino, LR., \& Brennan, MG2016, Disaster preparedness in Philippine nurses. Journal of 
Nursing Scholarship, 48(1), pp: 98-105.

Lim, G.H., Lim, B.L., \& Vasu, A., (2013), Survey of factors affecting health care workers' perception towards institutional and individual disaster preparedness. Prehospital and Disaster Medicine, 28(4), pp: 353-358.

Sangkala, M.S., Gerdtz, M.F. (2018), Disaster preparedness and learning needs among community health nurse coordinators in South Sulawesi Indonesia. Australasian Emergency Care, 21(1), pp:23-30.

Sonneborn, O., Miller, C., Head, L., Cross, R., 2018, Disaster education and preparedness in the acute care setting: A cross-sectional survey of operating theatre nurse's disaster knowledge and education.
Nurse Education Today, 65, pp:23-29.

Tzeng, W., Feng, H., Cheng, WT., Lin, CH., Chiang, LC., Pai, L., \& Lee, CL2016, Readiness of hospital nurses for disaster responses in Taiwan: A cross-sectional study. Nurse Education Today, 47, pp: 37-42.

Usher, K., Mills, J., West, C., Casella, E., Dorji, P., Guo, A., Woods, C2015, Cross-sectional survey of the disaster preparedness of nurses across the AsiaPacific region. Nursing Health \& Science, 17(4), pp: 434-443.

Yan, YE., Turale, S., Stone, T., \&Petrini, M2015, Disaster nursing skills, knowledge and attitudes required in earthquake relief: Implications for nursing education. International Nursing Review, 62(3), pp:351-359. 